\title{
DESAIN FASILITAS BANGUNAN HUMANIS DALAM MENINGKATKAN KENYAMANAN TK AN-NUR
}

\author{
Edwin Santoso ${ }^{1 *}$, Melisawati Susetyo ${ }^{2}$, Tiffany Kusuma ${ }^{3}$, Luciana Kristanto $^{4}$ \\ 1,2,3,4 Fakultas Teknik Sipil dan Perencanaan, Universitas Kristen Petra \\ Jl. Siwalankerto 121-131, Surabaya 60236 \\ Email: 1131197edwin@gmail.com; ²melisasusetyo@gmail.com; 3tiffany.kusuma@yahoo.com; 4lucky@petra.ac.id \\ *Penulis korespondensi
}

\begin{abstract}
Abstrak: Bangunan publik seperti sekolah adalah tempat bagi anak-anak untuk tumbuh, melakukan beberapa kegiatan, dan berinteraksi dengan yang lain. Lingkungan belajar yang baik dapat mengoptimalkan pertumbuhan anak. TK AN-NUR adalah salah satu sekolah di Surabaya yang belum mengoptimalkan fasilitas sekolahnya. Ini adalah alasan mengapa penulis memilih topik ini untuk menganalisis apa yang harus diperbaiki untuk membuatnya lebih baik. Oleh karena itu, penulis menyarankan untuk memperbaiki dan menambahkan beberapa elemen untuk meningkatkan kenyamanan belajar dan bermain untuk lingkungan anak-anak di sekolah itu.
\end{abstract}

Kata kunci: Sekolah TK, kenyamanan belajar, fasilitas, anak-anak

\begin{abstract}
Public building such as school is place for children to grow, to do some activities, and to interact with the others. A good study enviroment can optimize children growth. AN-NUR Kindergarten is one of the school in Surabaya which has not optimized their school facilities. These are the reasons why the writers chose this topic to analyze what should be fixed to make it better. Therefore, writers suggest to fix and add some elements to improve learning comfort and playing for children environment in that school.
\end{abstract}

Keywords: Kindergarten, learning comfort, facilities, children.

\section{PENDAHULUAN}

Sekolah merupakan "rumah kedua" bagi anakanak. Sebagian waktu yang dihabiskan anak-anak untuk beraktivitas adalah di sekolah. Dalam hal ini, sekolah merupakan hal yang penting dalam diri anak untuk dapat mengembangkan potensi dan karakter anak itu sendiri. Pada tahapan usia Golden Age, yaitu usia tiga hingga enam tahun, anakanak mulai mengoptimalkan pertumbuhan dan perkembangannya. Maka dari itu, pemilihan sekolah Taman Kanak-Kanak (TK) didasarkan pada tahapan usia anak dimana anak dapat lebih mengenali diri mereka. (Lebond, 7 Desember 2017).

Berdasarkan buku yang ditulis oleh Mark Dudek (2006) yang berjudul "Schools and Kindergarten", dituliskan bahwa anak-anak merupakan jantung dunia. Anak-anak harus mendapat perhatian agar dapat berkembang dengan baik. Salah satu faktor yang mempengaruhi perkembangan anak tersebut adalah bangunan. Bangunan yang dibangun harus merupakan bangunan yang meresponi semua yang dibutuhkan anak-anak dalam beraktivitas. Maka dari itu, seorang arsitek harus bisa memandang apa saja yang dibutuhkan anak-anak agar mereka dapat beraktivitas dengan baik, serta mengerti hal apa saja yang dapat meningkatkan perkembangan anak. Bangunan yang humanis bagi anak harus bisa mencerminkan seluruh karakter anak agar anak bisa lebih mudah beradaptasi dengan lingkungan sekitar, dan mereka dapat merasa nyaman ketika berada di bangunan tersebut. (Dudek, 2006, p. 9) Sekolah TK AN-NUR merupakan sekolah yang akan dijadikan sebagai objek dalam melakukan pengabdian masyarakat. Sekolah tersebut merupakan salah satu sekolah TK di Surabaya yang memiliki fasilitas kurang memadai dalam mendukung kegiatan belajar dan bermain anak. Dengan demikian, dilakukan survei untuk mengamati tingkat kenyamanan anak dalam melakukan aktivitas di sekolah. Namun kembali lagi, fasilitas yang kurang memadai menjadi salah satu faktor yang dapat menurunkan kinerja anak, dan faktor inilah yang akan dibahas lebih lanjut.

Usulan perbaikan desain fasilitas penunjang pendidikan menjadi salah satu cara yang dapat dilakukan untuk meningkatkan kualitas pendidikan di sekolah TK AN-NUR. Fasilitas-fasilitas yang kurang layak dapat diperbaiki atau diperbaharui. Tidak hanya fasilitas dari elemen arsitektural, ruang luar juga dapat menjadi salah satu media pembelajaran bagi anak. Ruang luar yang dirancang dengan baik akan meningkatkan suasana anak untuk bersosialisasi dengan baik juga. Seluruh 
upaya tersebut guna memenuhi kriteria desain sekolah yang humanis. (Kliment, 2001, pp. 14-20)

Keterlibatan lingkungan dan fasilitas di sekolah adalah guru dengan segala potensinya (kecerdasan, kepribadian, komitmen, kerajinan); kondisi sekolah (luas lahan, banyaknya permainan, kerajinan); keberadaan teman; aturan-aturan di sekolah; sikap orang tua dan masyarakat sekitar. Pada saat tersebut anak mulai mengenal dunia luar dengan komunitas yang lebih luas. Sekolah yang baik harus menciptakan hubungan harmonis antar seluruh komponen yang ada di dalamnya termasuk fasilitas pembelajaran di dalamnya. (Masnipal, 2013)

\section{PELAKSANAAN ABDIMAS}

Tabel 1. Tahapan Pelaksanaan Abdimas

1. Pengamatan Seberapa nyaman anak dalam melakukan aktivitas di sekolah yang berhubungan dengan arsitektur

2. Kegiatan yang Mengobservasi aktivitas anak dan dilakukan perilakunya dalam Taman KanakKanak yang sudah ada dalam kurun waktu yang sama

3. Lokasi Abdimas TK AN-Nur, Jl Siwalankerto Timur no $213 \mathrm{~A}$

4. Waktu kegiatan Dilakukan 3 kali, yaitu pada tanggal 9, 11, dan 15 Januari 2018, pada waktu operasional sekolah, yaitu pukul 08.00 - 10.00 WIB.

5. Hasil kegiatan Usulan perbaikan desain

\section{DATA EKSISTING DAN ANALISA}

\section{Data Bangunan Sekolah TK AN-NUR}

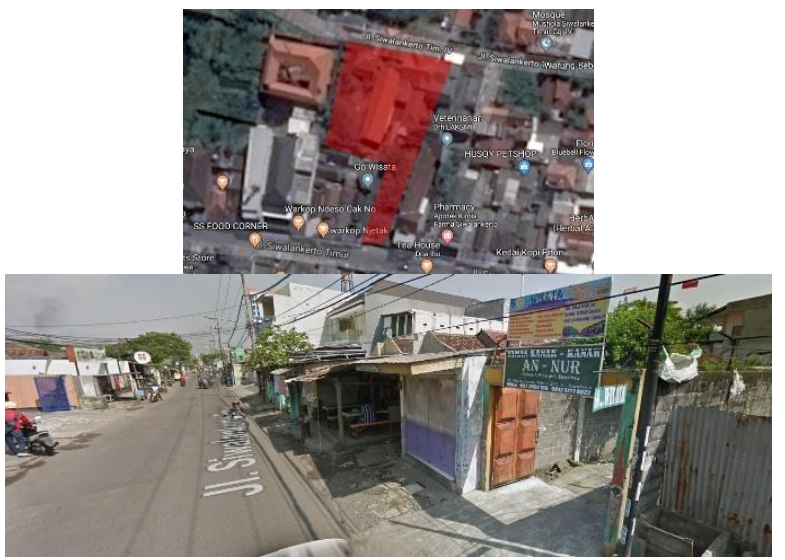

Gambar 1. Letak Sekolah TK AN-NUR (Sumber: googlemap.com, 2018)

Taman Kanak-Kanak "AN-NUR"

- Lokasi: Jalan Siwalankerto Timur nomor 213 A, Surabaya

- Fungsi: Lembaga Pendidikan Taman KanakKanak

- Tahun Pembangunan: 1984 - 2014

- Luas Lahan / Luas Bangunan: $\pm 1.500 \mathrm{~m}^{2} / \pm 468$ $\mathrm{m}^{2}$
- Jumlah Jenjang Pendidikan: 2 (TK A dan TK B)

- Jumlah Staf dan Guru: 3 Pengajar, 2 Staf dan 1 Kepala Sekolah

- Jumlah Murid / Kelas: 12 Murid / Kelas

- Fasilitas Bangunan: Ruang Staf - Guru, Ruang Kelas, Ruang Luar, Toilet dan Gudang

- Jam Operasional: 07.15 - 10.30 WIB

- Aktivitas Murid Pasca Pembelajaran: Belajar membaca, menghitung, mewarna, bermain, membuat kerajinan tangan, dll.

\section{Konteks Lingkungan}

TK AN-NUR berlokasi di jalan Siwalankerto yang banyak dilewati kendaraan. Kondisi masyarakat di daerah tersebut rata-rata adalah kaum pekerja. Pencapaian ke bangunan hanya melalui gang, yang dapat diakses dari jalan raya Siwalankerto. Walaupun lahan sekolah TK tersebut terletak di dekat jalan raya, namun bangunan berada jauh dari jalan raya, yaitu berjarak sekitar 40 meter.

\section{Zoning dan Sirkulasi}

Terdapat 4 zoning, yaitu entrance, area peralihan, area guru dan staff, dan area anak-anak. Area entrance dan peralihan dapat dijangkau oleh semua orang, area guru dan staff hanya dapat dijangkau oleh karyawan sekolah dan beberapa orang tertentu saja yang boleh masuk area tersebut, sedangkan, area anak-anak hanya dapat dijangkau oleh anak-anak dan guru TK AN-NUR.

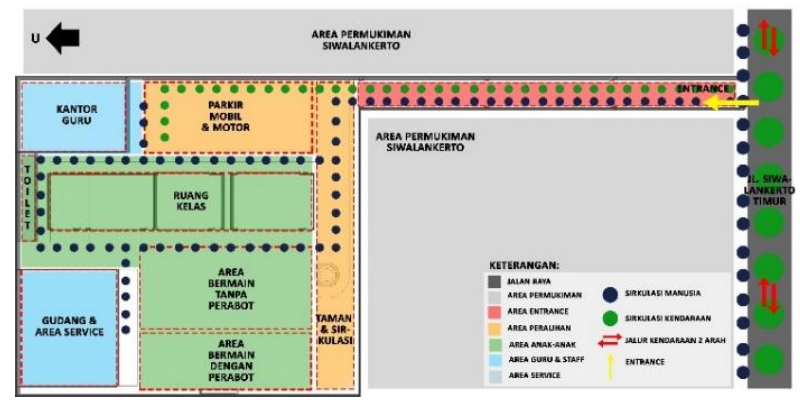

Gambar 2. Zoning dan Sirkulasi (Sumber: Dokumentasi pribadi, 2018)

\section{Dimensi dan Bentuk Bangunan}

Bentuk bangunan, baik denah maupun tiga dimensi merupakan bentukan yang sangat sederhana, sehingga tidak ada ruangan yang terbuang. Bangunan dengan dua ruang kelas di dalamnya memiliki dimensi $28.2 \mathrm{~m}$ x $5.85 \mathrm{~m}$. Kedua ruang kelas tersebut dipisahkan oleh sebuah lorong kecil dengan lebar 1 meter. Ukuran ruang kelas pertama adalah $8.7 \mathrm{~m} \times 5.85 \mathrm{~m}$. Ruang kelas kedua adalah $18.5 \mathrm{~m}$ x $5.85 \mathrm{~m}$. Ruang itu lebih besar karena dibagi lagi menggunakan pembatas papan menjadi 2 ruangan. 


\section{Kondisi Eksisting}

a. Fasilitas Pembelajaran

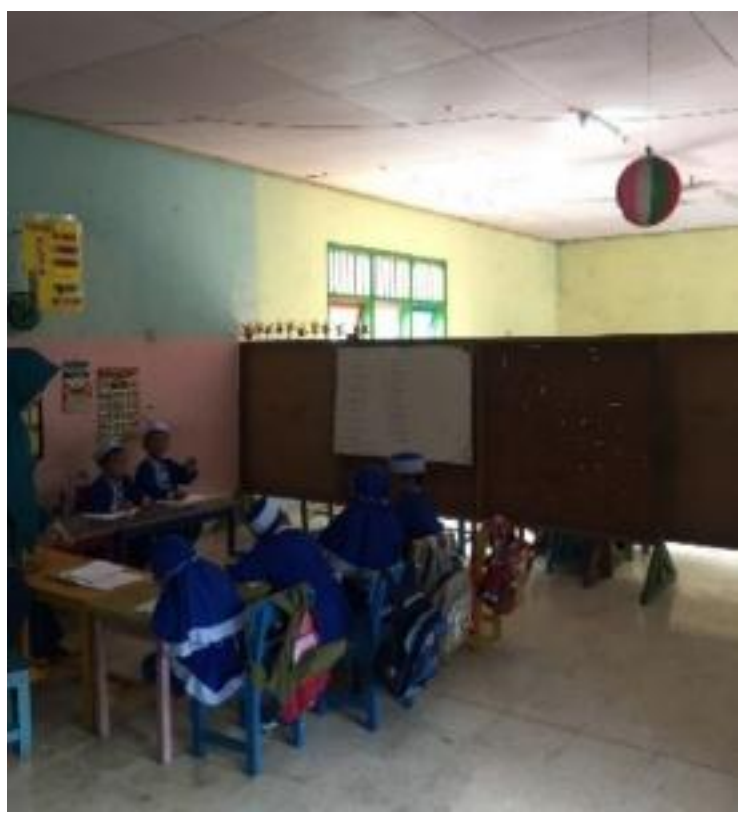

Gambar 3. Suasana Kelas TK A (Sumber: Dokumentasi pribadi, 2018

b. Fasilitas Permainan

Fasilitas permainan yang ada di TK AN-NUR ini berupa lapangan dengan luas $320 \mathrm{~m}^{2}$.
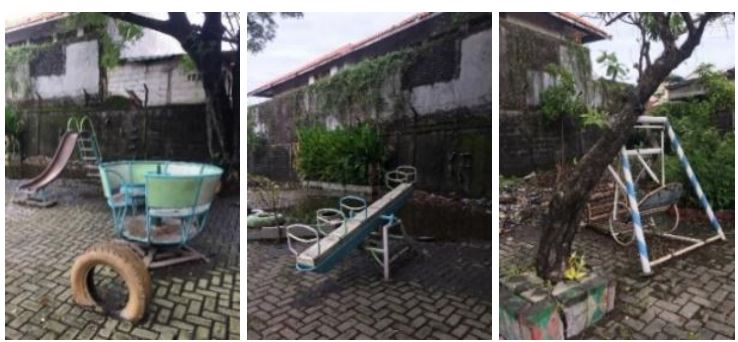

Gambar 4. Fasilitas Permainan di Lapangan (Sumber: Dokumentasi pribadi, 2018

c. Suasana Kelas

Suasana ruang kelas kurang memadai, media gambar sudah mulai pudar dan kotor, selain itu suasana dalam kelas juga terasa gelap dan kurang penghawaan karena bukaan sangat minim.

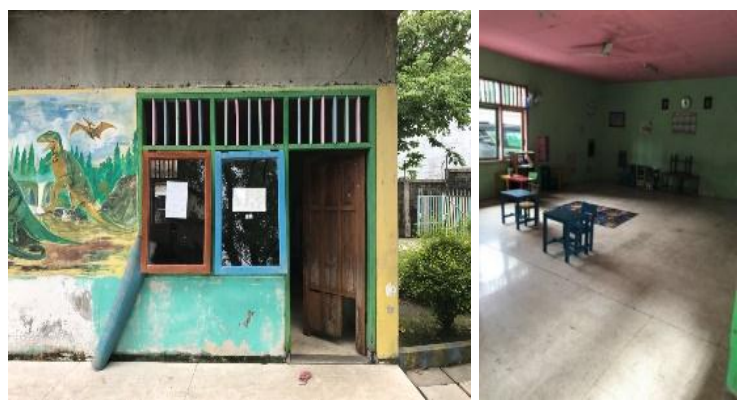

Gambar 5. Dinding Luar Bangunan dan Ruang Kelas (Sumber: Dokumentasi pribadi, 2018)

\section{Analisa Desain Bangunan terhadap Kriteria Se- kolah TK yang BaikBerdasarkan Kliment (2001)}

Tabel 2. Analisa Desain TK AN-NUR berdasarkan Kriteria

\begin{tabular}{l} 
No. Kriteria \\
\hline 1. Lingkungan fisik sekolah TK \\
dibutuhkan ruang luar dan \\
ruang dalam yang didesain \\
dengan aman, bersih, \\
menarik, dan terlihat luas.
\end{tabular}

Analisa

Terdapat empat jenis mainan yang tidak layak pakai lagi, sehingga anak lebih senang berlarian di lapangan. Namun, hal tersebut tidak diimbangi dengan keamanan yang cukup. Ruang kelas sudah aman tetapi kurang menarik dan bersih.

2. Area yang memiliki aktivitas Area antara ruang kelas TK A 1 harus diberi pembatas dan TK A 2 hanya diberikan dengan area yang tidak ada partisi berupa papan tulis yang aktivitasnya, misalnya diberi menyebabkan perambatan partisi, pagar, dll. kebisingan.

3. Lantai dan injakan kaki Lantaimenggunakan keramik harus keras, seperti pada sisi dalam bangunan. penggunaan pada kayu. Ruang luar menggunakan paving.

4. Furnitur harus bebas dari Perabot yang digunakan, seperti ujung yang tajam, agar aman meja dan kursi sudah aman, bagi anak-anak. tidak memiliki sudut yang tajam.

5. Material yang digunakan Dinding bangunan dicat namun dalam bangunan harus tidak membahayakan anakaman, tidak terlalu banyak anak. mengandung bahan kimia.

6. Terdapat area privat, baik di Tidak terdapat area privat pada dalam ruangan maupun luar sisi dalam maupun luar ruangruangan, agar anak bisa menemukan jati diri mereka.

7. Ruangan untuk pekerja Ruangan untuk para pekerja haruslah nyaman, terorgani- dipisahkan dari bangunan kelas. sasi dengan baik, dan dalam Ruangan itu tidak mampu keadaan yang baik juga. menampung enam staf dan pengajar dengan layak.

8. Satu kelas yang baik maksimal terdiri dari 20 murid per kelas. Satu kelas terdiri dari 8 dan 12 murid per kelas. Kelas sudah tergolong baik.

9. Material maupun finishing Tidak terdapat material material sebaiknya dapat mereduksi kebisingan, agar suara antar kelas tidak terlalu terdengar dengan jelas. maupun finishing material yang dapat mereduksi kebisingan karena pembatas antara kelas TK A 1 dan TK A 2 hanyalah papan tulis.

10. Menciptakan ruangan untuk Area bermain luar telah setiap aktivitas yang berbeda, dibedakan dengan ruang kelas contohnya, area bermain dibedakan dengan ruang kelas. sehingga menciptakan ruangan untuk setiap aktivitas yang berbeda.

11. Sediakan ruang pajangan. Dinding kelas menjadi area Memajang karya anak-anak untuk memajang karya anaksangat diperlukan, agar orang tau perkembangan anak tersebut.

12. Entrance harus terasa menyambut. Akses untuk masuk ke bangunan harus jelas dan dibuat berbeda dengan ruang-ruang lainnya.

13. Pilih warna dinding yang Warna yang digunakan di kelas sesuai dengan tema. Namun TK AN-NUR sudah merupakan akan lebih baik jika menggunakan warna terang seperti merah, hijau, biru, merah muda, kuning, dan warna terang, namun warnawarna tersebut banyak yang pudar akibat kotor. 


\section{USULANDESAIN}

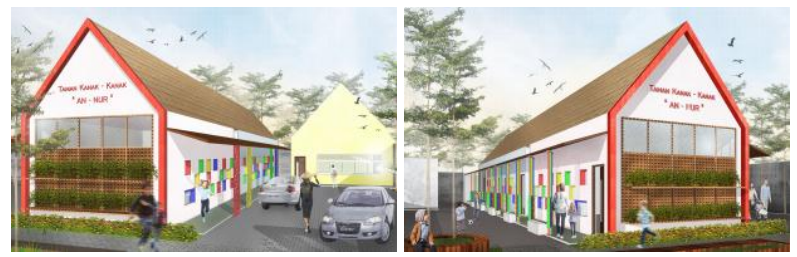

Gambar 9. Perspektif Rencana Renovasi Desain Sekolah TK AN-NUR

a. Konsep Desain

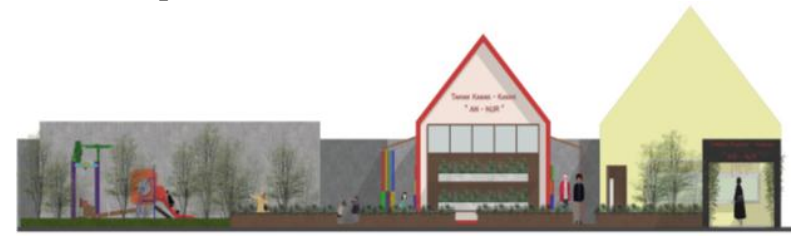

Gambar 10. Tampak Depan Usulan Desain Bangunan

Konsep yang diusulkan adalah pembelajaran di dalam dan luar ruangan, fleksibilitas, dan interaksi antara elemen arsitektur dan aktivitas anak. Dengan adanya pembelajaran di dalam dan luar ruangan, anak-anak akan lebih bisa terbuka dan mengenal alam sekitar. Fleksibilitas diterapkan dengan menggunakan ruangan yang multi fungsional. Interaksi antara elemen arsitektur diterapkan agar anak dapat belajar mengenal huruf, angka, dan warna melalui elemen arsitektur yang ada.

b. Usulan Desain

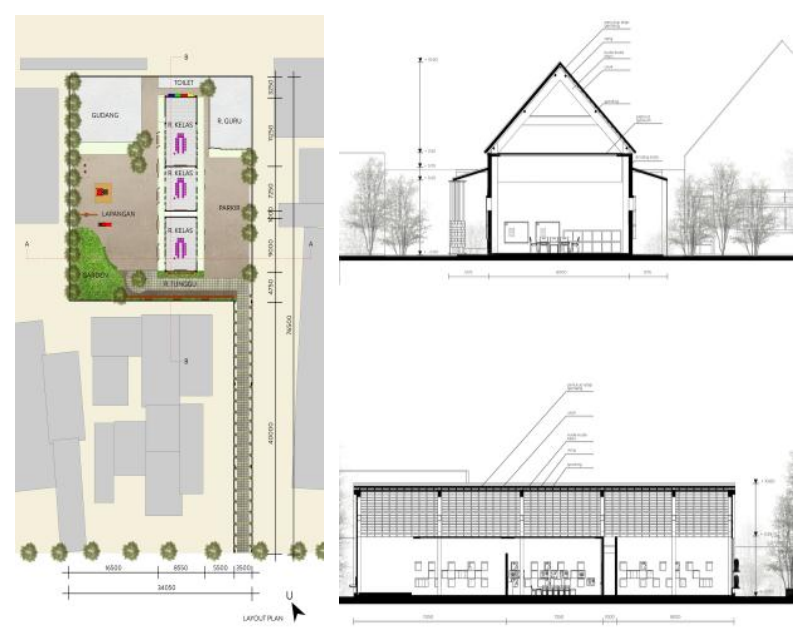

Gambar 12. Denah, Potongan A-A, Potongan B-B Usulan Desain

- Fasilitas Pembelajaran Dalam Ruangan

Ruang kelas didesain banyak bukaan yang berbentuk persegi yang diatur secara acak. Terdapat bukaan yang tidak ditutup kaca (pada bagian atas yang digunakan untuk memasukkan cahaya dan udara), dan juga terdapat bagian yang tertutup kaca (untuk memasukkan cahaya).

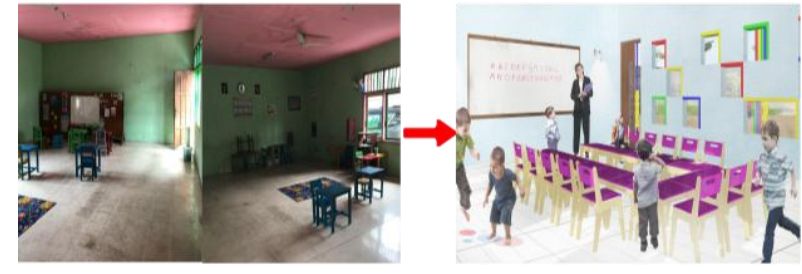

Gambar 13. Desain Ruang Kelas Sekarang dan Usulan Desain

- Fasilitas Pembelajaran Luar Ruangan

Dalam meningkatkan pembelajaran, diusulkan untuk membuat sebuah area di luar ruang kelas yang hijau dan bersih yang membuat suasana sejuk. Anak-anak dapat duduk di atas rumput sambil mendengarkan guru mengajar, juga dapat bermain dan bergerak dengan leluasa dengan mendapatkan matahari yang cukup untuk pertumbuhan anak. Selain itu, diusulkan juga suatu elemen arsitektur yaitu kisi-kisi yang dapat dimanfaatkan untuk mereduksi intensitas cahaya yang masuk sekaligus sebagai media bermain dan belajar anak.

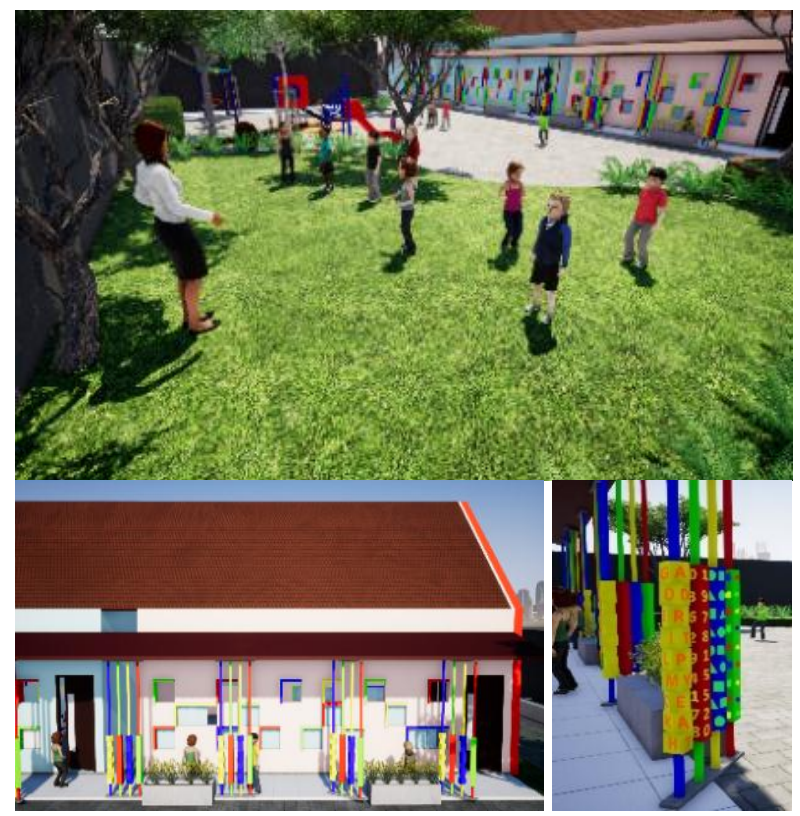

Gambar 14. (Atas) Area Belajar di Luar Kelas, (Bawah Kiri) Kisi-kisi sebagai Alat Belajar anak, (Bawah Kanan) Detail Kisi-kisi

- Fasilitas Bermain dan Ruang Luar

Area bermain tersebut dibagi menjadi dua bagian. Bagian pertama yaitu bagian area bermain dengan menggunakan alat-alat permainan dan bagian lainnya adalah lapangan kosong sebagai area serbaguna.

Area masuk didesain menarik dengan diberi tanaman bambu yang ditempatkan di samping kiri dan kanan dan gantungan bambu yang dapat bergerak sehingga menimbulkan bunyi untuk memicu anak mengenal bunyi itu. 


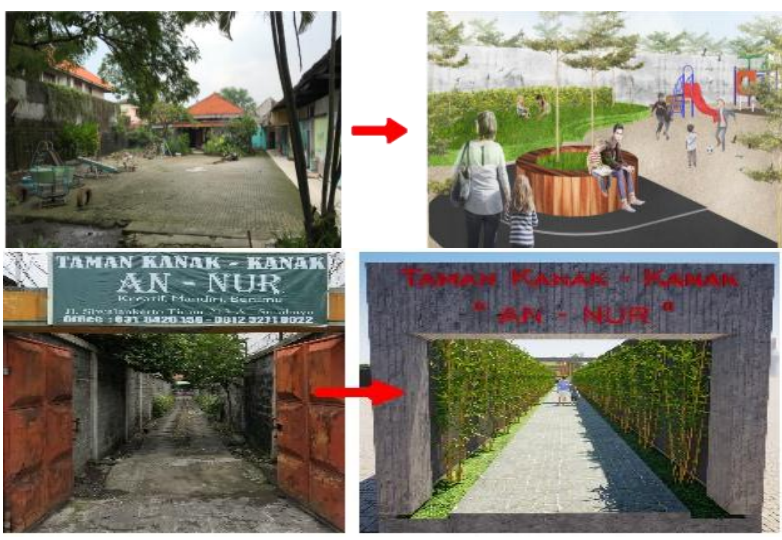

Gambar 15. Desain Fasilitas Bermain dan Entrance Sekarang dan Rencana Renovasi Desain

\section{PENUTUP}

Kegiatan Abdimas ini telah dilakukan dengan inisiatif mahasiswa dan usulan desain telah diberikan kepada sekolah TK AN-NUR pada fasilitas pembelajaran dalam ruangan dan luar ruangan serta fasilitas bermain dan ruang luar sekolah. Wujud dari usulan desain berupa penataan bukaan pada dinding ruang kelas, penyediaan ruang terbuka hijau, penambahan elemen permainan, dan perbaikan area pintu masuk sekolah TK AN-NUR.
Semua usulan tersebut diharapkan mampu meningkatkan kemampuan anak dalam bermain dan belajar mengenal huruf, angka, bentuk, dan warna sehingga desain yang humanis pada TK ANNUR dapat memenuhi kriteria sebagai sekolah yang dapat secara optimal mengembangkan potensi dan karakter anak.

\section{DAFTAR PUSTAKA}

Chandra, S. M. 2011. Konsep Perencanaan dan Perancangan. Pusat Penitipan dan Pendidikan Anak Usia Dini di Yogyakarta, 149-150.

Dudek, M. 2008. A Design Manual Schools and Kindergartens. (R. Stein, Ed.) Basel, Switzerland. The Deutsche Nationalbibliothek.

Kliment, S. A. 2001. Building Type Basics for Elementary and Secondary Schools. Canada. Library of Congress Cataloging-in-Publication Data.

Lebond, B. 7 Desember 2017. Mengenal Golden Age atau Masa Tumbuh Kembang Anak. https://psyline.id/mengenal-golden-age-masatumbuh-kembang-anak/. Diakses tanggal 23 November 2018.

Masnipal. 2013. Siap Menjadi Guru dan Pengelola PAUD Profesional. Jakarta. PT Elex Media Komputindo. 